\title{
O counseling em benefício do discipulado cristão
}

\section{Counseling for the benefit of christian disciples}

Francisco Antônio Morilhe Leonardo*

Resumo: O presente artigo visa destacar a relevância do Counseling em benefício da construção da personalidade dos indivíduos, na qual o aconselhamento contribui para o discipulado cristão. Ademais, enfatizase o sentido de ser pessoa construtora, formadora e como o principal ator no desenvolvimento cristão, pois essa ferramenta vem para ser um diferencial para aqueles que desejam ter o conhecimento da palavra de Deus, além de influenciar na permanência dessas pessoas na igreja, contribuindo com a manutenção da fé cristã. Entretanto, considerando as mais diversas fases da vida, na variação dos relacionamentos humanos sociais, os seres humanos passam por situações, às vezes, conflitivas que, sozinhos, parecem não poder lidar com estas e não conseguem enfrentá-las. Desse modo, observa-se que o Counseling, no sentido pastoral, tem por objetivo contribuir com a reflexão acerca da condição em que a pessoa se encontra para, posteriormente, ajudá-la na tomada de uma decisão, sendo o ajudador ou discipulador um colaborador que ajudará nessa reflexão com a comunicação interpessoal

\footnotetext{
* Mestre em Direito e Educação pelo Centro Universitário Eurípedes de Marília-SP - UNIVEM. Email: kiko_marilia@hotmail.com.
} 
de seu ajudado ou discípulo, mostrando os possíveis caminhos a serem seguidos, fundado a partir do exposto na sessão de aconselhamento.

Palavras-chave: Counseling Pastoral; Discipulado; Discipulador; Comunicação Interpessoal

Abstract: This article aims to highlight the relevance of Counseling in favor of the construction of the personality of individuals, in which counseling contributes to Christian discipleship. In addition, it emphasizes the sense of being a constructive, formative person and as the main actor in Christian development, since this tool is to be a differential for those who wish to have the knowledge of the word of God, besides influencing the permanence of these people in the church, contributed to the maintenance of the Christian faith. However, considering the most diverse stages of life, in the variation of social human relationships, human beings go through situations, sometimes conflicting situations that, alone, seem to be unable to deal with these and can not face them. In this way, it is observed that Counseling, in the pastoral sense, aims to contribute to the reflection about the condition in which the person finds himself and, later on, helps him in making a decision, the helper or disciple being a collaborator who will help in this reflection with the interpersonal communication of his help or disciple, showing the possible paths to be followed, based on the above in the counseling session.

Keywords: Pastoral Counseling; Discipleship; Discipler; Interpersonal Communication

\section{Introdução}

O discipulado é um fato presente na fé cristã e tem sido interpretada de maneiras diferentes, cuja variedade de explicações, nesse contexto, tem sido tão 
variada que se permite, também, interpretar esse elemento voltado naquele que se relaciona com o discipulador, aprendendo ou recebendo conselhos a fim de buscar a melhor maneira para satisfazer a situação-problema em que a pessoa está passando. A interpretação do discipulado não deve se afastar da significação que a teologia traz, dada pela própria tradição do cristianismo, e também de sua função educativa, pois isso não fortaleceria a identidade cristã ao exercício da fé.

Tal prática tem sido um assunto de interesse aos adeptos do cristianismo, embora ela seja mais atraente, cujo intuito é captar mais pessoas para o conhecimento da palavra de Deus, bem como a sua permanência, e não somente a casualidade de uma prática educativa. Dessa forma, vislumbram-se programas e atividades envolvendo o discipulado, mais frequentemente em igrejas que se organizam por meio de pequenos grupos que se dedicam à prática do discipulado cristão.

Nesse panorama, o Counseling Pastoral é considerado um processo interativo entre duas pessoas, o discipulador e o discipulado, cujo escopo é daquele que propicia a habilitação do discipulado em tomar uma decisão em relação a escolhas de cunho pessoal. Nesse viés, processa-se de maneira interativa visando auxiliar a pessoa a se organizar melhor, estimulando-a encontrar os melhores caminhos em relação às variadas situações existenciais que dificultam momentos de suas vidas.

Destarte, essa ferramenta busca, também, contribuir no incremento de uma personalidade sadia voltada ao crescimento humano nos mais variados campos, na qual socialmente está inserto, como a área pessoal, profissional, afetiva entre outras; por fim, onde há a necessidade de se interagir melhor e ter um consequente resultado positivo e melhorar a qualidade de vida em todas as searas, inclusive a espiritual.

Assim, a proposta do Counseling Pastoral é ofertar a ajuda confiável focada na relação humana, gerando confiabilidade, sendo esta duradoura e transformadora, amparando o discípulo a se descobrir naquilo que ele possa vir a ser, sendo distinto daquilo que momentaneamente é. Por esse prisma, o objetivo deste se define na medida em que retrata a função primordial do discipulado, focado no que a pessoa busca, não ultrapassando os limites que adentram as áreas 
patológicas que carecem de outro tipo de experiência profissional, como a ajuda de psicólogos ou de psiquiatras.

O Counseling Pastoral alia-se à visão do discipulado cristão resultando numa fusão muito importante uma vez que une as questões psicológicas com as teológicas, buscando conduzir o outro a obter melhor discernimento e clareza em fatos que momentaneamente não consegue resolver por si só. Nesse diapasão, a fim de diminuir essa dicotomia, o counseling pastoral aborda profissionalmente e pessoalmente com objetivo próprio no desenvolvimento do ser humano e visa a aperfeiçoar suas capacidades, auxiliando as pessoas na maneira de lidarem com tais obstáculos, gerando, consequentemente, um resultado favorável.

Por fim, destaca-se, por relevante, que se realizará uma pesquisa qualitativa, cujo enfoque é dedutivo e fundar-se-á no levantamento bibliográfico, a ter como ponto de partida o discipulado na visão cristã, além da definição do counseling e de sua modalidade pastoral, aliada ao discipulado. Além do mais, salienta-se a importância dessa ferramenta norte-americana, testificada como um meio primacial, a fim de que propicie as pessoas lidarem com situações em que a escuta e, posteriormente o aconselha, para se criar mecanismos aptos a produzir resultados sempre positivos.

\section{O discipulado sob o prisma Cristão}

Foi em Antioquia, no primeiro século da era cristã, que os discípulos de Jesus Cristo receberam o nome de cristãos (BÍBLIA, 1997). Dessa forma, o cristão, se escolher ser seguidor de Jesus Cristo, opta por seguir o Salvador. Assim como a comunidade primitiva, os cristãos da atualidade devem prosseguir com o mesmo objetivo daqueles, mesmo com as mudanças rápidas e profundas presentes no mundo, o que acaba dificultando a continuidade do evangelho de Jesus.

Em linhas gerais, o discípulo é aquele que aprende de um mestre e o segue. Nos evangelhos, o discípulo é uma pessoa chamada por Jesus Cristo para segui-lo, fazendo a vontade de Deus a ponto de aceitar até mesmo a possibilidade de uma condenação. Como consequência desse discipulado, os seguidores de 
Jesus são chamados a uma vida amorosa entre eles e uma postura de humildade e confiança em Deus (BÍBLIA, 1997).

Em sintonia com isso, o discipulado é um princípio bíblico que, recentemente, foi dado relevância pela teologia pastoral e a espiritualidade cristã, devido sua importância nos Evangelhos e nos Atos dos Apóstolos. A circunstância para se encontrar uma maneira de levar alguém a interiorizar o foco do discipulado em sua caminhada cristã e a compreensão de que a opção em seguir os ideais do cristianismo tem a ver com o seguimento de Jesus no conjunto de discípulos se pressupõe que esse caminho se inicie numa experiência subjetiva, de modo geral, devocional e protetiva.

Entretanto, o discipulado, bem como as palavras que dão origem ao mesmo (discípulo, discípula), é um tema importante a ser discutido na igreja hodierna: a palavra aparece mais de duzentas e cinquenta vezes no Novo Testamento, protagonizando discussões sobre crescimento, vida espiritual e amadurecimento (WILLARD, 2008).

A palavra discipulado no Antigo Testamento era halak que literalmente conotava "ir atrás de". No Novo Testamento, discipulado remete à ideia de akolouteo, traduzida por seguir. Outra palavra encontrada é mathetés (discípulo). Outro termo relacionado ao discipulado é mimeomai (imitar) (MUNIZ, 2012). Frisa-se que um dos princípios do discipulado está atrelado a uma união empenhada e pessoal, em que um discípulo mais experiente contribui com outros a fim de se aproximarem mais de Jesus e, assim, se tornarem discípulos.

A opção pelo discipulado é, portanto, o comprometimento individual com Jesus Cristo, a renúncia a todos os legalismos mundanos diante da graça daquele que o chama, transmite conhecimento e depois envia. Como se pode constatar, o modelo estrutural de discipular e ser discipulado tem uma lógica religiosa voltada para a multiplicação e o domínio numérico, territorial e simbólico das cidades, na qual se vê a missão de "Fazer discípulos fazedores de discípulos" (HUBER, 2009a, p. 62).

É certo que, levar o Evangelho é um dos desafios do discipulado, pois não se trata somente de passar a informação do conhecimento bíblico ao discípulo. 
Dessa forma, o discipulador precisa se ater ao fato de que, para comunicar a palavra de Deus precisa estar à disposição de seu discípulo. Logo, o discipulado é um meio de ensino e um modelo de ações que ajudam na construção e reprodução de princípios espirituais no cotidiano cristão.

Cabe destacar que, Jesus os chama para que estejam com ele, para que sejam seus amigos, compartilhem de sua vida e não para que se tornem somente servos (BÍBLIA, 1997). Assim, "treinar um discípulo é fazer dele uma pessoa completa, um crente maduro. Jesus, enquanto viveu, ensinou os doze, pois visava a sua transformação: sua meta era fazer a vida crescer" (RICHARDS, 1980, p. 26). De igual sorte, compreende-se que o discípulo não vai somente se tornar seguidor de Jesus, mas vai aprender a palavra, de maneira teórica e prática.

Dessa forma, o discípulo não é um servo sendo que o discipulado condiciona à amizade e ao amor ensinado por Jesus, por isso que a obediência, nesse caso, advém de algo voluntário, prazeroso e não apenas o de realizar serviços por obrigação, como escravos (CANELLATO, 2018).

Ademais, Jesus convidou seus discípulos para um relacionamento mais profundo, íntimo, de vivência de amizade, como uma família, respeitando mutuamente e compartilhando sentimentos. Outrossim, destaca-se a reflexão de Jesus sobre o amor cristão ao dizer que "já não vos chamo servos, mas amigos" (BÍBLIA, 1997). Nesse diapasão, pode-se vislumbrar o sentido da amizade verdadeira, ou seja, ao modo de Jesus.

Em síntese, o discipulado é aquele que acata os conselhos de um mestre e os seus ensinamentos, cuja essência se acha no cumprimento, pelo discípulo, do dever de ser testemunha do seu Senhor durante toda a sua vida. O autor destaca, sob o ponto de vista bíblico, muitos exemplos do discipulado. No Antigo Testamento, o conceito de servo era mais comum e está incluído no discipulado, como em Josué, que "era servo de Moisés"; "Eliseu era servo de Elias"; "Geazi era servo de Elizeu"; "Baruque era servo de Jeremias"; "O profeta Isaías tinha os seus discípulos” (BÍBLIA apud HUBER, 2009b).

Em consonância com os textos bíblicos, o autor destaca o modelo de discipulado no Novo Testamento, ressaltando a passagem dos "Os discípulos de 
João - o batista; "Os discípulos dos Fariseus, na qual Paulo foi discípulo de Gamaliel”; "os Discípulos de Jesus, como os doze apóstolos e os Setenta"; “outros discípulos de Jesus: José de Arimatéia, Ananias de Damasco" e os Cristãos de Antioquia” (BÍBLIA apud HUBER, 2009b).

Cabe destacar que, o discipulado exerce função relevante e sua visão reflete na realidade social, política e econômica, uma vez que contribui com a solução de problemas nessas áreas, pois o grande pilar e onde se encontram tais respostas é a palavra de Deus, e uma das missões dos discipuladores é apresentála para aqueles que ainda não a conhecem.

Acerca do benefício que o discipulado traz às realidades políticas, econômicas e sociais, Canellato (2018) afirma que se deve buscar a pró-atividade de soluções para os problemas encontrados, com bom ânimo, pois, como Jesus que venceu o mundo e não desfaleceu frente às dificuldades encontradas no discipulado, os cristãos são coparticipantes da sua vitória na cruz e, assim, vencerão. Portanto, com as bases lançadas, desafios postos, caminhos analisados, cabem aos cristãos lutar para que o evangelho continue avançando em direção ao alvo.

Em resumo, pode-se inferir que o exercício do discipulado é um ensino recorrente do modelo cristão, no qual Jesus se apresenta nos evangelhos doutrinando seus discípulos, pois na Bíblia se encontra a multiplicação dos discípulos e o próprio desenvolvimento das instituições cristãs que seguem até a atualidade incentivando este tipo de prática.

Ademais, com o discipulado, se objetiva organizar a sociedade em torno de valores que se buscam visando a uma vida honrada em que é necessário o desenvolvimento de uma ação relacional entre as pessoas com princípios que se norteiam perante a uma atitude prudente diante dos entraves diários.

\section{O Counseling Pastoral}

Inicialmente, cabe destacar que o counseling apresenta algumas qualidades de cunho teológico, visando a um aconselhamento em benefício de uma relação de ajuda. Assim sendo, o counseling pastoral objetiva relacionar a psicologia e a teologia, intercedendo nesses campos do conhecimento. Dessa 
maneira, pode-se definir o counseling, num sentido pastoral, de acordo com Danon (2003) como sendo:

[...] um processo de interação entre duas pessoas, counselor e cliente, cujo objetivo é aquele de habilitar o cliente a tomar uma decisão em relação a escolhas de caráter pessoal', o counseling é um conjunto de habilidades, atitudes e técnicas para 'ajudar a pessoa a ajudar-se'. Partindo do pressuposto de que uma pessoa já tem em si os recursos necessários, propõe-se criar as condições para fazê-los emergir (DANON, 2003, p. 25).

A relação de ajuda refere-se a qualquer tipo de profissão que implique ajuda através da relação, desde ensino à psicoterapia: o Counseling refere-se a todas as formas de aconselhamento, à exceção de situações no âmbito da psicopatologia. O Counseling proporciona o desenvolvimento dos recursos internos, visando uma melhoria das relações e da qualidade de vida (QUATTRINI, 2002, p. 02).

Trazendo para a realidade a que se trata esta pesquisa, pode-se ter por nomenclatura a figura do counsellor ou ajudador como o discipulador, e o ajudado ou cliente, diz respeito ao discípulo. Ajudar a ajudar-se, por meio da relação, é o significado de counseling como se entende na Associação Italiana de Counseling, segundo a experiência de vários anos. Esta definição, segundo Quattrini (2002) tem várias implicações:

1) $O$ counsellor não detém um conhecimento que é um poder sobre o cliente. O conhecimento de ambos tem igual validade. É somente porque o cliente pede a participação do counsellor que este intervém propondo pontos de vista diferentes, a fim de facilitar as mudanças requeridas pelo cliente. Se o cliente não os aceita, não significa que esteja enganado: tem o pleno direito de manter apenas a sua perspectiva. $O$ counsellor também tem o direito manter a sua posição, e de declarar-se incapaz de intervir nas condições do cliente.

2) O counsellor, para "ajudar através da relação" deve estar na relação, reconhecer-se como estando no campo onde o cliente se encontra (a teoria do campo de Lewin), em relação empática com o mesmo, ou seja, sob o mesmo horizonte de eventos, por oposição "a estar debaixo do horizonte de eventos".

3) O counsellor pode fornecer opiniões, mas não é deontologicamente correto que forneça conselhos, mesmo se a pedido do cliente. 
4) A função do counsellor é ajudar o cliente a reconhecer e aceitar estas diferentes partes, e fazer com que estas aprendam a dialogar e a compreender-se.

5) A capacidade mais significativa que o ser humano tem para ajudar-se é considerada a criatividade. Uma função fundamental do counsellor é promover no cliente a ativação da criatividade, que se entende como uma atitude inata, eventualmente pouco desenvolvida, mas potencialmente acessível a todos (QUATTRINI, 2002, p. 02).

Por esse prisma, o auxílio do counseling, na visão pastoral, advém da relação de ajuda, pois o indivíduo, nesse caso, encontrará caminhos a fim de neutralizar os fatores negativos que o fragilizam, afastando-se de pressões externas e internas e, consequentemente, adquirindo melhor qualidade de vida.

Contudo, é uma abordagem para a saúde mental que une recursos espirituais e psicológicos para a cura e o crescimento e assiste as pessoas quando “devem enfrentar e resolver os próprios problemas, tendo presentes por um lado a preparação psicológica e por outro a preparação ética, espiritual e religiosa" (DANON, 2003, p. 205).

O counselor (orientador, mentor) pastoral não é, segundo Danon, um simples confessor. Antes, é alguém capacitado teoricamente tanto com conceitos teológicos quanto comportamentais. O counselor não precisa ser, portanto, um líder religioso, mas alguém que tem formação e experiência em ambas as áreas (DANON, 2003, p. 205).

Entretanto, percebe-se que o counseling não se trata de um debate que visa impor-se àquele que detém de mais conhecimento na tentativa de forçar uma resposta voltada para acomodar o ajudado. Dissonante a isso, uma das peculiaridades desse modelo de ajuda é contribuir com aquele que busca ajuda a encontrar-se e ter autonomia, abrindo os horizontes para novas alternativas na vida, seja qual for a carência, possibilitando à pessoa, crer na capacidade de construir-se.

Em sintonia com isso, o conceito de relações de ajuda, como sendo "as relações nas quais pelo menos uma das partes procura promover na outra o crescimento, o desenvolvimento, a maturidade, um melhor funcionamento e uma maior capacidade de enfrentar a vida", ou ainda certa ocasião na qual um dos 
participantes "procura promover numa ou noutra parte, ou em ambas, uma maior apreciação, uma maior expressão e uma utilização mais funcional dos recursos internos latentes do indivíduo" (ROGERS, 1985, p. 43).

A evangelização diz respeito à pregação acerca da salvação em Cristo, que leva a pessoa a se reconciliar novamente com Deus, tendo, consequentemente, os pecados perdoados. Dessa forma, o conselheiro cristão deve estar cheio de compaixão e amor por aqueles que procuram ajuda por meio do aconselhamento, na qual o counseling se alia a esse processo, tornando-se um caminho de amor, de Deus, para com as pessoas. Neste diapasão, Hurding (1995) relata que:

Se o nosso aconselhamento for cristocêntrico, então nosso trabalho de alcançar, na relação de aconselhamento, os outros, no mundo exterior, será sempre um veículo de amor de Deus às pessoas. O cliente poderá reagir de forma positiva e bem especifica ao convite de Cristo para receber perdão e nova vida e a seu desafio de viver para ele. Esse cliente poderá dar passos vacilantes em direção a essa entrega dentro do processo de aconselhamento (HURDING, 1995, p. 15).

Nesse caso, com tal ferramenta voltada em prol da evangelização, vislumbra-se a mudança psicológica de todos os atores, as pessoas teriam maior autonomia e dignidade, de modo que teriam melhor compreensão de si mesmos no seu contexto, fazendo escolhas construtivas e agindo melhor a partir dessas escolhas (ROGERS, 1989).

Em última análise, compreende-se que a proposta do counseling pastoral é proporcionar uma ajuda confiável focada na relação humana, de forma duradoura e transformadora, encorajando a pessoa a se descobrir no que ela pode vir a ser, mudando a situação que momentaneamente se encontra, pois se busca levá-la a obter melhor discernimento e entendimento em situações que não consegue por si só resolvê-las. 


\section{O Counseling Pastoral em benefício da visão do discipulado Cristão}

O counseling, palavra traduzida literalmente por aconselhamento em nosso idioma, não se reduz somente em dar conselhos ou apresentar "receitas prontas" e dar soluções. Esta ferramenta norte-americana apresenta uma excelente dinâmica de ajuda objetiva às pessoas que estão vivendo um conflito, seja de ordem espiritual, afetiva, familiar, relacional e econômica. Ao se trazê-la para a função do discipulado Cristão, pode-se afirmar que esta ensina e contribui para o desenvolvimento das habilidades da ajuda ao próximo.

O counseling, em prol do discipulado, por analogia, pode-se afirmar que o ajudado é aquele que está sendo discipulado, ou seja, o discípulo sendo a pessoa que "se sente em conflito, confusa, perdida, faltando algo, e, isso, pode ser em qualquer seara da vida, seja na emocional, física, afetiva, profissional, intelectual ou espiritual". Já o ajudador, ou o discipulador, é aquele que sabe ajudar a si mesmo, que "se ama profundamente, possui habilidades de ajuda e se coloca à disposição para ajudar o outro e amá-lo incondicionalmente" (ROSSI, 2012, s/p).

Nesse sentido, aliando o counseling ao discipulado, testifica-se que, aqueles que discipulam também aprendem com seus discípulos, pois se trata de um aprendizado mútuo, se ajudam entre si perante as dificuldades cotidianas, formando, assim, um círculo maior de amor e de relacionamentos interpessoais significativos.

A “centração" sobre o outro supõe as seguintes atitudes: interesse aberto (disponibilidade sem preconceitos a priori); atitude de não julgamento, avaliações, críticas ou conselhos; intenção autêntica de compreender (que significação a situação tem para o outro; atitude não diretiva, o outro faz emergir o discurso); esforço para a objetividade; não defesa e lucidez sobre seus próprios sentimentos (SALOMÉ, 1994).

Nessa ocasião, portanto, o counseling ajuda a viver o problema do próximo, respondendo às questões dentro do problema do outro, refletindo para o discípulo o que ele mesmo disse, na qual ele conseguirá ver os caminhos satisfatórios 
e, nessa experiência, com autonomia, conseguirá progredir nas mais variadas searas da vida. $\mathrm{O}$ ato de escutar e de responder são os alicerces do counseling.

Cabe destacar que, a fim de que seja feito um trabalho satisfatório em benefício do discipulado, utilizando o counseling, baseado na obra de Feldman e Miranda (2013), destacam algumas posturas relevantes:

Empatia: capacidade de se deslocar no lugar do outro, de modo a sentir o que se sentiria caso se estivesse em seu lugar.

Aceitação incondicional ou respeito: capacidade de acolher o outro integralmente, sem que lhe sejam colocadas quaisquer condições e sem julgá-lo pelo que sente, pensa, fala ou faz.

Coerência: capacidade de ser real, de se mostrar ao outro de maneira autêntica e genuína, expressando, através de palavras e atos, seus verdadeiros sentimentos (FELDMAN; MIRANDA, 2013, p. 38).

Ao se iniciar a operacionalização das dimensões do discipulador e dos efeitos por elas provocados nos discípulos, desenvolver-se-á o modelo de Ajuda que engloba as atitudes do discípulo durante a fase de mudança e, as habilidades do discipulador que propiciam essa mudança, que são visíveis, mensuráveis e transmissíveis. Entretanto, são atitudes do discipulador:

Sintonizar: entrar em sintonia com o ajudado, comunicando-lhe, de maneiras não verbais, disponibilidade e interesse;

Responder: comunicar, corporal e verbalmente, compreensão pelo ajudado;

Personalizar: mostrar ao ajudado sua parcela de responsabilidade no problema que está vivendo;

Orientar: Avaliar, com o ajudado, as alternativas de ação possíveis e facilitar a escolha de uma delas (FELDMAN; MIRANDA, 2013, p. 55).

Destarte, no counseling pastoral, à medida que o discipulador sintoniza, responde, personaliza e baliza o discipulado, este começa a se comportar de forma a prover sua própria mudança na área pessoal em que necessita, por meio das seguintes fases, de acordo com as atitudes do discipulado. Tais fases são descritas da seguinte forma: 
Envolver-se: capacidade de se entregar ao processo de ajuda; Explorar: capacidade de avaliar a situação real em que se encontra no momento do processo de ajuda - definir com clareza onde está;

Compreender: estabelecer relações de causa e efeito entre vários elementos presentes em sua vida, perceber a sua responsabilidade na situação que está envolvido e definir aonde que chegar;

Agir: movimentar-se do ponto onde está para onde que chegar, estabelecendo o plano de ação para saber como chegar lá (FELDMAN; MIRANDA, 2013, p. 78).

A relação de ajuda no counseling quer ensinar o saber ouvir numa atitude empática, no desejo de estar na relação, respeitando o outro por inteiro, conhecendo-se a si primeiro e as suas dificuldades e vulnerabilidades, pois "ouvir empaticamente é ouvir atentamente, exigindo um investimento emocional na outra pessoa e uma relativa abertura para nossos próprios sentimentos" (CLINEBELL, 1987, p. 74-75).

Nessa linha de pensamento, o ajudador poderá aprender a viver com aquilo que está acontecendo, não buscando respostas prontas para o problema que é levado ao counselor, pois “quando tudo muda ao seu redor, é necessário um ponto de referência bem enraizado para não se perder. E este ponto de referência bem enraizado pode ser somente interno, pode ser apenas a própria consciência" (DANON, 2003, p. 213).

A empatia nessa relação permite que se adentrem, também, aos caminhos que levam para se sentir a dor do próximo e sua tensão. Daí, “a vida e o contato com as pessoas na relação de entrevista nos colocam brutalmente frente à dor e à angústia do homem” (MILLETTE, 1982, p. 20).

O objetivo do counseling não retira o necessário cuidado que evita qualquer tipo de precipitação e aceleração, visando chegar mais rápido a um fim. Muitas das vezes não é o fato de falar ou o agir rapidamente com respostas precipitadas que garantem os resultados de um aconselhamento, mas sim, o silêncio reflexivo que possibilita aos envolvidos, a escuta de si mesmo e do próximo.

Posto desta maneira a questão, o caminho exige proporcionar e possibilitar o discípulo a crer que é possível mudar uma realidade que ele está 
passando naquele momento e mudar esse cenário, dando abertura a um projeto existencial de valorização da própria vida e seus âmbitos.

No counseling damos a oportunidade à pessoa de pensar-se, para sair de encurralamentos em que se colocou devido a um pensar fragmentado que não permite integrar determinadas ocorrências como audácia adjunta a sua personalidade. Quando você ouve o pensamento sente uma pessoa consciente, que é o seu interior mais profundo, por trás ou por baixo do pensamento (TOLLE, 2005, p. 11).

Cabe salientar que o counseling pastoral se propõe, também, a despertar maior atenção aos fatos presentes do que aos passados, capacitando a mudar o ponto de vista das coisas, dando oportunidade a um novo sentido da vida e, assim, mudar o comportamento. Além desse fator, sem relevar as estruturas da personalidade, destina-se o foco na pessoa e não no problema apresentado.

O counseling utiliza-se da palavra como meio de relação de confiança e abertura e também o saber ouvir através de uma "escuta ativa". Como base, encontra-se a confiança no crescimento e evolução do outro sem coerções e a liberdade para se expressar. Assim, são fundamentais nessa relação; a acolhida, a observação de linguagens não verbais, a sinalização do entendimento do outro, reformulando e devolvendo o que se captou e, sobretudo o saber silenciar. Atento a esses requisitos, "a relação de ajuda no counseling desenvolve frutos de mudança, autonomia e um novo sentido à vida" (NETO, 2016, p. 12).

No panorama social em que a sociedade está se transformando, e ao mesmo tempo, "onde o equilíbrio e o bem-estar individual repercutem sobre aquele da coletividade", vê-se um florescer de uma nova forma de auxílio psicológico ao homem nele inserido. É dado que "a sociologia não estuda mais a sociedade na sua estrutura piramidal hierárquica, mas sim, na sua intensa e entranhada rede inter-relações”, e por isso, faz-se necessário investir no indivíduo e suas capacidades, visando a uma psicologia "que saiba guiar o indivíduo até um contato mais profundo consigo mesmo, com as próprias necessidades, com as próprias capacidades escondidas ou esquecidas, e chegar, enfim, a uma maior confiança em si mesmo" (DANON, 2003, p. 33-34). 
A propósito, a atração é o caminho de um discipulado eficiente, pois estimula a pessoa a "trabalhar duro e responder apropriadamente para ter a aprovação do discipulador, cumprindo as condições colocadas por ele" (SILVA, 2009, p. 85). A personalidade é modelada nos encontros, já que a atenção é relacionar-se com o discípulo à base de paternidade espiritual. Logo, o relacionamento é um fato primordial para o discipulado.

Assim, teoricamente, o counseling pastoral busca o conhecimento e a compreensão de si mesmo, inicialmente, para que assim possa dar amparo ao discípulo, ajudando-o a compreender e solucionar seus problemas, buscando soluções conjuntas, diferentemente do que normalmente se faz. Ao aspecto prático, supõe-se um treinamento das habilidades destacadas, como a escuta e a relação interpessoal.

Para Collins (2004, p. 17) o aconselhamento objetiva dar estímulo e orientação às pessoas que estão enfrentando decisões difíceis, perdas ou desapontamentos. Uma das tarefas do conselheiro cristão é "levar as pessoas a ter um relacionamento pessoal com Jesus Cristo. O objetivo final é ajudar os outros a se tornarem discípulos de Cristo e a discipular outras pessoas".

Portanto, o counseling se configura como um novo modelo de encarar os entraves da vida, valorizando a relação e os recursos de cada um, pois se crê que a melhor maneira de se ajudar alguém é ajudá-la a entender a própria situação e a conduzir a situação; assumindo, com autonomia, a responsabilidade pelas escolhas. Logo, comunicar-se bem consigo mesmo, com a vida e com o próximo revela a chave de mudança e de novas decisões.

\section{Os conceitos do Counseling para a relação de ajuda entre o discípulo e o discipulador}

Em se tratando do discipulado, o counseling permite beneficiar essa relação de ajuda sob alguns pontos importantes a serem destacados. Primeiramente, a fim de se abrir os caminhos da percepção, o discipulador deve estar em sintonia com seu discípulo. Assim, de acordo com Feldman e Miranda (2013), o primeiro elemento que counseling traz para esse ideal diz respeito ao 
fato de estar sintonizando com a pessoa e, sintonizar-se se traduz em preparar o ambiente para sua recepção, pois é onde o discípulo (ajudado) será atendido.

Por esse fato, é viável que o ambiente seja propício para o bem estar do encontro, onde o ambiente deve favorecer transmitindo "paz interior". Assim sendo, Feldman e Miranda, (2013) destacam a importância da decoração do local, ou seja, combinar as cores do ambiente, a disposição dos móveis de maneira adequada, o fato de manter o ambiente limpo e bem conservado, os objetos decorativos relacionados com o ajudado, oferecer pequenos cuidados ao ajudado a fim de eliminar o desconforto e garantir privacidade.

Em seguida, o discipulador deve-se ater ao fato da acolhida, recebendo a pessoa calorosamente ao se iniciar o encontro, cujo intuito é transmitir receptividade e interesse, de modo que ele se sinta valorizado. Posteriormente, cabe ao discipulador (ajudador) atendê-lo, transmitindo-lhe mensagens corporais de interesse e disponibilidade a fim de transmitir-lhe mensagens de interesse, de modo a envolvê-lo no processo de ajuda (FELDMAN; MIRANDA, 2013).

Nesse viés, tal ação deve ser realizada pelo discipulador (ajudador) aproximando e ficando de frente, inclinando o corpo para frente, mantendo contado visual, mantendo a fisionomia receptiva, concentrando e assentindo com a cabeça, tocando e mantendo a mesma altura do discípulo (ajudado) (FELDMAN; MIRANDA, 2013).

Em seguida, destaca-se a ação de observar, ou seja, usar os olhos para captar as mensagens não verbais transmitidas pelo discípulo (ajudado), cujo objetivo é observá-lo e verificar a possibilidade de se receber mensagens significativas acerca do que ele está vivendo, de modo a conhecê-lo melhor. Isso deve ser realizado olhando a aparência do ajudado, bem como seu comportamento, de modo a inferir o nível de energia, o sentimento, a prontidão, o relacionamento e a coerência (FELDMAN; MIRANDA, 2013).

O próximo passo do primeiro elemento do counseling reside no fato de escutar, destacado os níveis da comunicação entre as pessoas numa conversa clichê, ou seja, aquela repetitiva, é aquela que se faz através de frases prontas e "chavões", não representam os sentimentos. Ademais, deve-se apenas captar as 
mensagens verbais transmitidas pelo discípulo (ajudado), para que a escuta possa permitir que ele diga tudo o que considera importante, de modo a compreendê-lo melhor (FELDMAN; MIRANDA, 2013).

Essa ação induz ao discipulador (ajudador) o fato deste ficar calado, não interromper, evitar distrações externas e internas (físicas e emocionais) e suspender os possíveis julgamentos (FELDMAN; MIRANDA, 2013). O objetivo principal é escutar e saber escutar pessoas, pois as habilidades que as pessoas mais dominam é o ato de falar e não de escutar.

Quando se aprende a escutar, se desperta o desejo de encontrar mais pessoas, no viés do discipulado cristão. A escuta envolve o silêncio interior, predisposição interna para se criar uma empatia real com o próximo e, sobretudo, a pessoa também irá se escutar de forma que conseguirá acatar o conselho do discipulador. Dessa forma, a realização de mudanças na vida do discípulo e, também, do discipulador fica mais fácil, pois, depois de aprender a escutar, aprende-se também, a responder.

Geralmente, aquele que não sabe escutar dá ao outro a resposta ao problema ou a uma simples pergunta, com uma teoria ou história que impressione mais do que a própria indagação, e, por consequência, há a desautorização do discípulo que se sente "perdido" porque ele continua a viver o problema ou a situação que continua sem resposta.

Sabendo escutar e observar e apreendendo os sentidos e mensagens sem reduzi-los a explicações formais ou dogmáticas, encaminhamos os ajudados, levando-os “assim a abrirem-se, circularem e entrarem em relação uns com os outros para que venham a ser condutores de vida" (SALOMÉ, 1994, p. 119).

Em seguida, o outro elemento que merece destaque no counseling, na relação de ajuda, é a resposta, de modo a abrir as portas da comunicação respondendo ao conteúdo, ao sentimento, ao comportamento, com imagens e com os próprios sentimentos. Mesmo verificando a relevância da definição da interação corporal entre as pessoas, não se pode olvidar de que a comunicação é realizada, basicamente, por meio da palavra. O discípulo (ajudado), ao finalizar cada uma de suas colocações verbais, espera um "feedback" do discipulador (ajudador), 
também verbal. É sabido que a necessidade básica daquele que busca ajuda é falar, mas chegará a hora em que ele vai querer e precisa escutar.

Dessa forma, respondendo ao conteúdo, o discípulo (ajudado), na maioria das vezes está "perdido" em seu próprio mundo. Uma das expectativas que ele tem do discipulador (ajudador) é que este o leve a encontrar um caminho. Então, responder ao conteúdo é buscar na fala do ajudado o verdadeiro motivo que o levou a se manifestar verbalmente ou até mesmo o motivo que o levou a procurar ajuda (FELDMAN; MIRANDA, 2013).

Cabe destacar que há efeitos gerados da resposta de conteúdo, pois na interação entre pessoas não existe causa sem efeito. O discipulador (ajudador) tem como missão básica compreender o discípulo (ajudado), que geralmente está confuso. Ele começa a se compreender, encontrando certa ordem em meio ao caos. Ademais, o tamanho da resposta deve ser sempre menor do que a colocação feita pelo discípulo (ajudado) (FELDMAN; MIRANDA, 2013).

Respondendo ao sentimento percebe-se o que o discípulo (ajudado) está sentindo a cada momento e deve-se comunicar essa percepção a ele, como se estivesse "vivendo" o problema do próximo. Essa tarefa só é possível na medida em que os sentimentos são também identificados e expressos pela própria pessoa ou com a ajuda de alguém capaz de percebê-los. Ao explorar e compreender a si própria, a pessoa atinge o autoconhecimento, que é, antes de qualquer coisa, o reconhecimento dos próprios sentimentos, e a mudança de maneira construtiva só acontece quando se conhece o suficiente para escolher a própria direção (FELDMAN; MIRANDA, 2013).

Nessa etapa, é importante reaprender a expressar sentimentos, uma vez que estes não se dividem em certos e errados, eles simplesmente existem como uma parte natural da própria condição humana. A comunicação dos sentimentos faz parte de uma relação construtiva. Os sentimentos não são imutáveis, conhecendo e descobrindo sua fonte, pode-se decidir trocar as emoções sentidas de forma que não sejam destrutivas. $\mathrm{O}$ ajudado não sabe o que está sentindo, ou sabe e não quer admitir para si mesmo, pois saber expressar seus sentimentos de 
maneira direta inclui nos relatos, não só os fatos e os sentimentos que experimentam diante desses fatos (FELDMAN; MIRANDA, 2013).

Destarte, deve-se preparar o discípulo (ajudado) para identificar seus sentimentos, cujas respostas de conteúdo que comunicar compreensão facilitarão a construção de um relacionamento firme e consistente para detectar esses sentimentos e discriminar o momento exato de comunicar suas próprias verdades. Logo, responder aos sentimentos traduz-se na habilidade de captar o que o ajudado está sentindo a cada momento e comunicar isso a ele (FELDMAN; MIRANDA, 2013).

Partindo-se da premissa de que respondendo ao sentimento e conteúdo encontra-se a somatória das duas habilidades anteriores, ou seja, quando o discipulador (ajudador) responde a sentimento e conteúdo, comunica o que compreende e, ao mesmo tempo, percebe como o discípulo (ajudado) está se sentindo e por que ele está se sentindo assim. A finalidade da resposta é comunicar a compreensão total da experiência do ajudado, nem a resposta de sentimento, nem a de conteúdo, isoladamente, são suficientes para se realizar essa comunicação (FELDMAN; MIRANDA, 2013).

Entretanto, destacam-se as respostas intercambiáveis que são as formuladas no mesmo nível em que o ajudado está se expressando, nem mais, nem menos. Já as respostas aditivas são aquelas em que ele acrescenta alguma coisa além daquilo que foi expresso pelo ajudado. As respostas subtrativas são as que subtraem alguma coisa à experiência do discípulo (ajudado), ou seja, que corta sua fala e o impede de continuar em sua auto exploração (FELDMAN; MIRANDA, 2013).

Nesse diapasão, há também as respostas empáticas, simpáticas e antipáticas. A resposta simpática ocorre quando a pessoa procura ser agradável a quem fala, mas desfocaliza inteiramente a experiência do outro, e passa para outro assunto. A resposta antipática também leva a pessoa a cortar o seu relato, mas é formulada de maneira desagradável, tendo uma conotação de crítica a pessoa. E a resposta empática é a única que dá permissão à pessoa para se expressar e continuar seu relato (FELDMAN; MIRANDA, 2013).

Destarte, respondendo com imagens, é o fato de que se sugere a representação daquilo que a pessoa relata, está vivendo ou sentindo. A imagem 
brota espontaneamente no discipulador (ajudador), é um poder muito maior de comunicar compreensão do que as respostas de conteúdo e sentimento. Através da imagem, ambos visualizam com enorme nitidez aquilo que o ajudado está vivendo e relatando (FELDMAN; MIRANDA, 2013).

Ao se responder ao comportamento encontra-se que se trata da habilidade de oferecer ao discípulo (ajudado) esses dados, nos momentos em que isso for benéfico para ele. Os dados corporais devem ser compatíveis com os dados verbais, de expressão e sentimento. Em seguida, respondendo às perguntas, é o elemento que serve de meio de comunicação de interação verbal entre as pessoas. As pessoas perguntam, pois precisam de respostas a fim de manter contato com o outro; porque querem expressar alguma coisa e não conseguem (FELDMAN; MIRANDA, 2013).

Ao finalizar esses elementos, salienta-se o fato de se responder com os próprios sentimentos cujo relacionamento não é entre dois papéis, mas entre duas pessoas vivendo um encontro verdadeiro. É importante que o discipulador (ajudador) saiba descriminar quais sentimentos devem ser comunicados e quando comunicá-los ao ajudado (FELDMAN; MIRANDA, 2013).

Em seguida, outro elemento da relação de ajuda apontado pelos autores Feldman e Miranda (2013) que pode beneficiar o discipulado remete a estar personalizando, ou seja, o fato de se abrir as portas da compreensão. Assim, devese mostrar ao discípulo (ajudado) sua parcela de responsabilidade diante da situação que está vivendo, facilitando sua compreensão do papel que desempenha no próprio problema de modo a poder resolvê-lo (FELDMAN; MIRANDA, 2013).

Esse elemento visa transformar a vítima em agente, sendo o ponto culminante do processo de ajuda com amadurecimento da pessoa, à medida que aumenta seu repertório da habilidade diante da vida. Nesse caminho, assumir a responsabilidade pelas emoções traduz-se em lidar com esses sentimentos de maneira saudável e não responsabilizar outras pessoas pelas próprias reações. As habilidades básicas de sintonizar e responder são as bases do personalizar no processo de ajuda, especialmente através das respostas intercambiáveis, aquelas 
que estão no mesmo nível em que o discípulo (ajudado) se expressa (FELDMAN; MIRANDA, 2013).

As fases do personalizar remetem-se ao fato de se dar respostas aditivas que internalizam cada vez mais os temas da fala do discípulo (ajudado). Nesse caso, leva-o a identificar a própria falta, assumindo inteira responsabilidade pela própria vida. Por fim, a fim de se personalizar o objetivo, último elemento do processo, a identificação vai possibilitar ao discípulo (ajudado) elaborar o seu programa de ação determinando a direção de sua mudança (FELDMAN; MIRANDA, 2013).

O último elemento apontado pelos autores é a ação de orientar, na qual se abrem as portas da realização. Assim sendo, orientar se traduz numa habilidade opcional, na qual todo processo de ajuda efetivo tem como resultado um ou várias mudanças por parte do discípulo (ajudado) tendo explorado sua situação insatisfatória e compreendido esta satisfação, pois ele elabora seu programa de ação. A partir deste processo de autoconhecimento, ele é capaz de personalizar sua própria experiência e a última decisão é dele. O discipulador (ajudador) o orienta, e ele escolhe seguir ou não sua orientação (FELDMAN; MIRANDA, 2013).

O significado da mudança é de que ninguém procura ajuda senão estiver pretendendo algum tipo de mudança em sua vida. Nenhum processo de ajuda terá sido efetivo se sairmos como entramos. A mudança interna e externa significa que a situação externa é passível de mudança, dando direção ao final do processo de ajuda. Por fim, os autores questionam se existe fim para o processo de ajuda. Portanto, pode-se concluir que o momento de parar chega quando o discípulo (ajudado) se transforma em discipulador (ajudador). Num processo efetivo, as habilidades de ajuda são assimiladas de tal forma pelo ajudado, que se tornam um estilo de vida (FELDMAN; MIRANDA, 2013).

Por fim, pelo exposto é possível constatar que as pessoas se responsabilizam por seus problemas desde que sejam acolhidas com a escuta empática e que possam se encontrar dentro do problema que tentam resolver por meio daquilo que o discipulador aconselhou. $\mathrm{O}$ counseling pastoral, voltado ao discipulado Cristão, tem por escopo o modelo de ajuda que permite o 
desenvolvimento dessas habilidades e, surpreendentemente, pode-se constatar que a pessoas que será ajudada primeiramente é o discipulador, ou seja, aquele que dá conselhos, para que depois, este aconselhará e ajudará aos seus discípulos.

\section{Considerações Finais}

Apresentou-se o estudo cujo foco destaca a importância do counseling para o discipulado cristão, ferramenta norte americana que une a psicologia e a teologia, a fim de auxiliar aqueles envolvidos nesse cenário, seja o discipulador e o discípulo, de modo a contribuir com a retomada de sua autonomia perante o problema que esteja momentaneamente passando.

Para tanto, destacou-se, primeiramente, o discipulado cristão em relação ao aconselhamento, visto na teologia e psicologia. Assim, destaca-se o amor mútuo e o zelo que Jesus deixou para a humanidade desenvolver e a essência de ajudar ao próximo, por meio do evangelho e das boas novas, numa relação comprometida e pessoal em que o discipulado é um meio eficiente para se aproximar do Salvador.

Por esse prisma, salientou-se a compreensão do counseling pastoral que visa compartilhar com o próximo a dimensão mais profunda e muitas vezes preciosa da vida, envolvendo o zelo como uma forma terapêutica do agir do discipulador, numa relação terapêutica que pretende levar cada pessoa ao progresso biopsicossocial e espiritual.

Dessa maneira, pode-se vislumbrar que o counseling pastoral pode contribuir para dar vivência cristã e a renovação àqueles que necessitam por meio do discipulado, pois permite lidar com meios de mudanças de identidade, aperfeiçoando-a e moldando o caráter, as posturas, os ideais e pensamentos, os sentimentos e as relações interpessoais beneficiando o bom comportamento das pessoas.

Identificou-se que, pode-se considerar o counseling uma ferramenta de ajuda no cotidiano das relações humanas, encontrando as peculiaridades específicas que atendem a pessoa, não como um problema e, sim como um ser em construção, apto a descobrir-se nos acontecimentos e, por consequência, a viver e 
conviver fatos que exijam pensar com criticidade e sentimentos que podem ser identificados com a contribuição do discipulador.

Por fim, seguindo os conceitos do counseling apontados por Feldman e Miranda (2013), voltado ao discipulado cristão, pode-se constatar que se trata de caminhos imprescindíveis para o sucesso do discipulado, de modo a "captar" mais pessoas para o Reino de Deus, facilitando apresentá-las para Jesus. Assim, a relação de ajuda pode contribuir com o desenvolvimento e maturidade, sendo uma habilidade a ser desenvolvida, na qual um aprende com o outro, devido à disponibilidade de escutar aqueles que precisam num sentimento de empatia.

\section{Bibliografia}

BÍBLIA. Português. Bíblia Shedd. Tradução de João Ferreira de Almeida. $2^{\circ}$ ed. Revista e atualizada no BRASIL. São Paulo: Vida Nova, 1997.

CANELLATO, Fábio. Reflexão sobre as características do discipulado adotado por Jesus. Revista Ensaios Teológicos, v. 3, n. 2, 2018.

CLINEBELL, Howard J. Aconselhamento pastoral: modelo centrado em libertação e crescimento. Tradução por Walter O. Schlupp e Luís Marcos Sander. 5. ed. São Leopoldo: Sinodal, 1987.

COLLINS, Gary R. Aconselhamento Cristão. São Paulo: Vida Nova, 2004.

DANON, Marcella. Counseling: uma nova profissão de ajuda. Curitiba: Sociedade Educacional e Editora IATES, 2003.

FELDMAN, Clara; MIRANDA, Márcio Lúcio de. Construindo a relação de ajuda II. Belo Horizonte. Editora Ceap. 2013.

HURDING, Roger F. A Árvore da cura: modelos de aconselhamento e de psicoterapia. São Paulo: Vida Nova, 1995.

HUBER, Abe. Aliança de Membresia: visão geral da Igreja da Paz, sua história, valores, projetos, requisitos para tornar-se membro e benefícios. Fortaleza: Premium. 2009a.

Discipulado um a um: Crescimento com qualidade. Porto Alegre: Adhonai, 2009b. 
MILLETTE, André. A entrevista psicológica na relação de entre-ajuda: psicologia, aconselhamento, counseling. 3. ed. São Paulo: Edições Paulinas, 1982.

MUNIZ, Raimunda Margarete Teixeira. O modelo do discipulado apostólico um a um da Igreja da Paz Central de Santarém-Pará: um diálogo com o aconselhamento pastoral. Trabalho Final de Mestrado Profissional. Mestrado em Teologia. Escola Superior de Teologia. Programa de Pós-Graduação. São Leopoldo/RS. 2012.

NETO, Júlio Pereira de Souza. O Counseling como Relação de Ajuda no contexto da Pós-Modernidade. Faculdade Vicentina. CEPPEV. Centro de Pós-Graduação, Pesquisa e Extensão Sociedade Educacional - IATES. Curitiba/PR. 2016.

QUATTRINI, Paolo. O significado de Counselling. Documento adaptado e traduzido de "II significato di Counselling". Março, 2002.

RICHARDS, Laurence O. Teologia da educação cristã. São Paulo: Vida Nova, 1980.

ROGERS, Carl R. Tornar-se pessoa. WWF Martins Fontes, 1985.

. Sobre o Poder Pessoal. São Paulo, Livraria Martins Fontes Editora. 1989.

ROSSI, Denílson. O que é relação de ajuda? 2012. Disponível em http://www.denilsonrossi.com.br/a-relacao-de-ajuda/. Acesso em 13 jul. 2018.

SALOMÉ, Jacques. Relação de Ajuda. Guia para acompanhamento psicológico de apoio pessoal, familiar e profissional. Tradução por Guilherme João de Freitas Teixeira. Petrópolis, RJ: Vozes, 1994.

SILVA, Aluízio A. 21 dias na vida de um discípulo: edificando relacionamento para o reino. Goiânia: VINHA, 2009.

TOLLE, Eckhart. Praticando o poder do agora. $3^{\mathrm{a}}$ ed. Rio de Janeiro, Sextante, 2005.

WILLARD, Dallas. A grande omissão: as dramáticas consequências de ser cristão sem se tornar discípulo. São Paulo: Mundo Cristão, 2008.

Recebido em: 23/07/2018

Aprovado em: 05/11/2018 